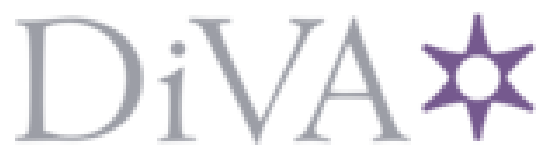

http://www.diva-portal.org

This is the published version of a paper published in LASE Journal of Sport Science.

Citation for the original published paper (version of record):

Piech, K., Carlson, R., Grants, J., Cherenkov, D., Gatatulin, A. et al. (2016)

Family Influence On Sport Activity Patterns During Early Adolescence: A Comparative Approach.

LASE Journal of Sport Science, 7(2): 3-15

https://doi.org/10.1515/ljss-2016-0012

Access to the published version may require subscription.

N.B. When citing this work, cite the original published paper.

Permanent link to this version:

http://urn.kb.se/resolve?urn=urn:nbn:se:gih:diva-4766 
ORIGINAL RESEARCH PAPER

\section{FAMILY INFLUENCE ON SPORT ACTIVITY PATTERNS DURING EARLY ADOLESCENCE - A COMPARATIVE APPROACH}

\section{Krzysztof Piech $^{1}$, Rolf Carlson ${ }^{2}$, Juris Grants ${ }^{3}$, Dmitriy Cherenkov ${ }^{4}$, Alexey Gatatulin ${ }^{5}$, Dzmitry Smaliakou ${ }^{5}$, Ulf Lindberg ${ }^{6}$}

${ }^{1}$ Academy of Physical Education Warzaw, Biala Podlaska Address: ul Akademicka 2, 21 - 500 Biała Podlaska, Poland

Phone: +48 607381070

E-mail: krzysztofpiech@wp.pl

${ }^{2}$ Swedish School of Sport and Health Sciences

Box 5626, S - 11486 Stockholm, Sweden

E-mail: carlsonrolf@gmail.com

${ }^{3}$ Latvian Academy of Sport Education

Address: 333 Brivibas Street, Riga, LV - 1006, Latvia

Phone: +37167543410

E-mail: Juris.Grants@1spa.1v

${ }^{4}$ Russian State University of Physical Education and Health

Address: 4, Sireneviy Boulevard, Moscow, 105122, Russia

E-mail: dmitriych61@ mail.ru

${ }^{5}$ Belarusian State University of Physical Culture

Address: 105 Pobediteley Avenue, 220020, Minsk, Belarus

Phone: +375 172508008

E-mail: oo@ sportedu.by

${ }^{6}$ Bosön Sport College, Sweden

Address: 18147 Lidingö

Phone: +4686996602

E-mail: ulf.lindberg@live.se

\section{Abstract}

The aim of research is to examine and describe young individuals who participate in extended sport education program. The main focus concerns family influences on the development of the investigated youngsters' sportive patterns. Data were collected through online and paper (whenever appropriate) questionnaires (elite sport training in secondary higher education - models of success in sport with pupils from a selection of sport schools in respective countries). Coaches from sports 
schools representing all participating countries (Poland, Sweden, Latvia, Russia and Belarus) were interviewed. The results indicate that the influence of parents and physical education teachers on the decision to join a sport club and to continue sport career is rather low. Main reasons behind joining a sport club are: the desire to become an athlete, sport idols, and the subjects' own will. Staying in a sport club and pursuing a career is also determined by previous achievements in the field and good coaches. The parents' past engagement in psychical activities was not systematic. The subjects consider local sport facilities and a number of accessible sport clubs and sports coaches to be of high importance at the early stage of their engagement in sport.

Key words: elite training, upper secondary education, sport career, family influence

\section{Introduction}

Competitive sport has developed in a majority of cultures and is one of the most common leisure activities among children and youth, regardless of cultural backgrounds or ethnic identities. To practice sport, which is connected to personal achievements, is becoming popular among children at a lower age than ever before. The universal value of sport is evident and great efforts are devoted to the search for and the development of sports talents. Most countries have over the years developed methods for talent acquisition and development. There are also collaborative structures between countries, including cooperation between governmental bodies.

Youngsters who participate in e-tended training programmes based on sport schools or sport classes under selective processes that ensure they are capable of enduring intensive training. Issurin noted, the work volume required to achieve first international successes by the Olympic champions on the average took $=3084 \mathrm{hrs}$ ( $\min 1840 \mathrm{hrs}-\max 4495 \mathrm{hrs}$ ) (Issurin, 2015). They must meet the criteria in motor and mental abilities as well as being talented. In order to involve them in sport and develop their physical abilities, it is not enough to create a proper environment for ractice. Family support is equally indispensable. Talent in competitive sport is generally regarded as a process from childhood to adult age, with an emphasise on the interaction between the developing person and the surrounding environment (Csikszentmihalyi, Rathunde \& Whalen, 1993; Soberlak \& Cotè, 2003; David, 2005; Kincer, 2005; Wolfenden \& Holt, 2005; Carlson, 2009). Search for and identification of talent at an early age can often be difficult. Selection is usually based on performance achievements during or before 
puberty. This infers great difficulties and risks of early-age drop-out rate. Early developers are favoured while late developers are left out based on factors beyond their own influence (Carlson, 2013). Malina (2015) statesthat: "Programs aimed at developing talented young athletes need to recognize several important features. First, talent development is a highly individualized and dynamic process. Second, the process is superimposed upon a constantly changing base, specifically the demands of physical growth, biological maturation and behavioral development and their interactions, as children pass from childhood into adulthood. Third, the process is exclusive; focus is often on the "most talented" individuals for a given sport or sport discipline/position, whereas many others are systematically excluded and/or voluntarily withdraw from the sport. Fourth, although some talent models view the developmental process as long term, paths to elite status are highly variable among individuals". Many of those young people deserve a second chance, a sort of talent recycling. Furthermore, research indicates that athletes who are successful internationally have practiced several sports simultaneously during early adolescence and got involved with their main discipline only in their midteens or later (Baker, Côté \& Deakin, 2005; Carlson, 2007). The purpose of this research is to examine and describe young individuals who participate in extended sport education programm. The main focus oncerns family influences on the development of the investigated youngsters' sportive patterns.

\section{Material and methods}

Financed by the Swedish Institute, the research project (Elite Sport Training in Upper Secondary Education - Models for Sportative Success) is a comparative study involving Russia, Belarus, Latvia, Poland and Sweden. A project group was established between leading universities in the field of physical education in respective countries. The project is led by prof. R.Carlson (Swedish School of Sport and Health Sciences, GIH, Stockholm). Data were collected through online and paper (whenever appropriate) questionnaires (elite sport training in secondary higher education - models of success in sport with pupils from a selection of sport schools in respective countries). Coaches from sports schools representing all participating countries were interviewed. Planning sessions took place in Riga, Latvia, and Moscow, Russia, at the end of 2012, as well as in Biala Podlaska, Poland, at the beginning of 2013. The collection of data commenced in March, 2013. In Poland the project included the group of young athletes who attended Sport Championship Schools or sport classes in secondary 
schools. The most prevalent disciplines were: basketball, football, handball, athletics and wrestling; and to a smaller degree table tennis, gymnastics and martial arts. The study involved 221 individuals -84 girls and 137 boys.

\section{Results}

The participants mostly originated from larger urban areas with 10 to 50000 inhabitants or more. A small percentage grew up in communities with 10000 residents or less. Early - life physical activities among the investigated youngsters varied by the sport they later specialized in. Hence, wrestlers, football-, basketball- and handball players had different sportive preferences during early adolescence. Furthermore, it is important to stress that the number of different types of psychical activities they engaged in childhood was rather low and unvaried. Figure 1. depicts the age at which the subjects entered organized sport. For most individuals this took place at the age of nine. Still there was number of subjects who engaged in organized sport at younger or at an older age.

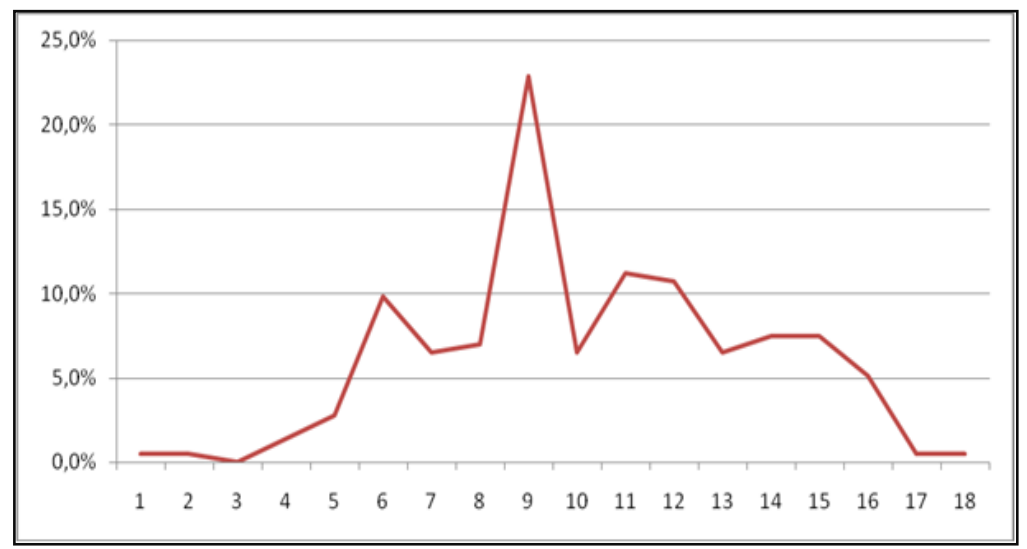

Figure 1. The age of sport debut

The research aims at determining the parents' role in the decision making process of their children with regard to joining a sport club. Some of the reasons mentioned by the subjects include their own will to join a sport club, a desire to become an athlete and their admiration for sport idols. Other educational environments, such as physical education teachers, friends, parents and siblings, played a much smaller role (fig.2). 


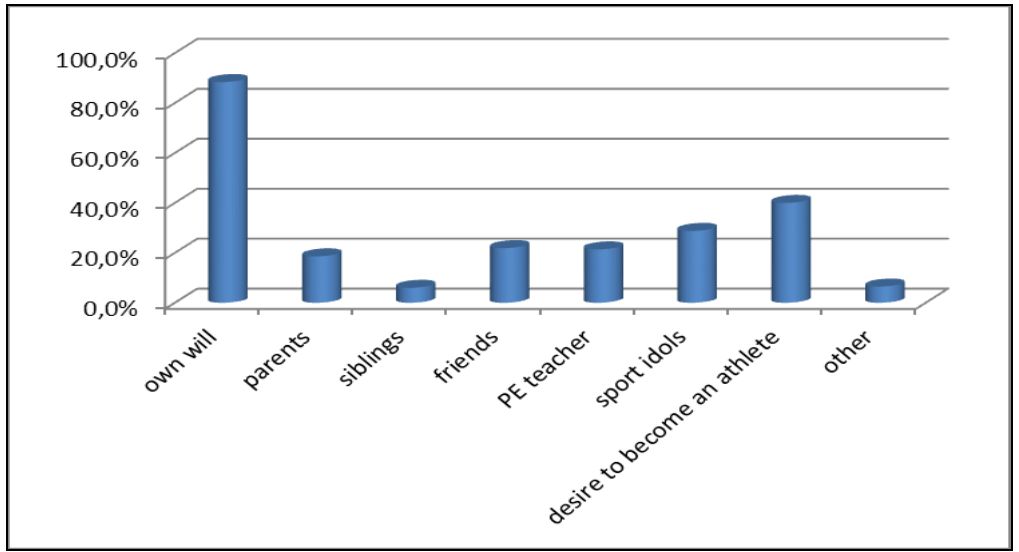

Figure 2. Main determinants of joining a sport club

The analyses of the next set of responses provide interesting data. The main reasons mentioned were good coaches and a will to become an athlete followed by early achievements in sports. Friends played a bigger role than sport idols. The impact of family, siblings, and physical education teachers seem to be of minor significance (fig. 3).

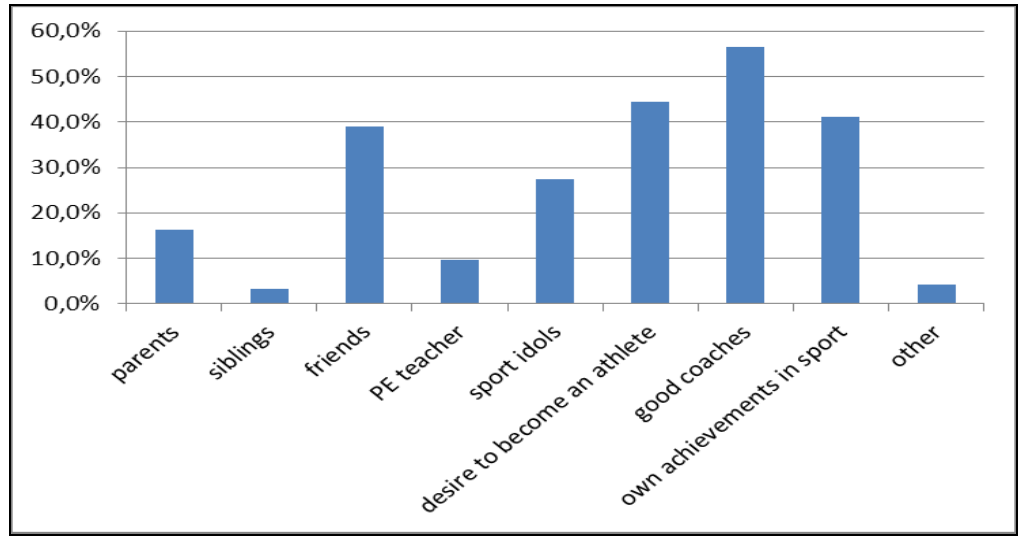

Figure 3. Main determinants behind remaining in a sport club

Data presented in Figure 4. concern the parents' involvement in sport. It is evident that fathers are more engaged in both competitive and amateur sports. A large percentage of the subjects' parents did not engage in sport at all, with mothers being significantly less active. 


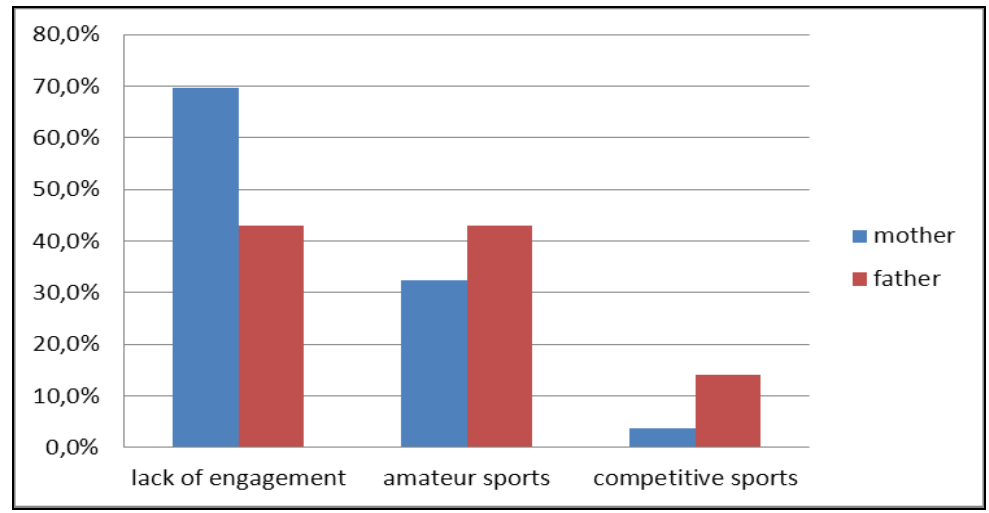

Figure 4. Parents' sport careers

Even if the parents engaged in sport together with their children, it was not in a systematic way. Parents did either not practice any physical activity at all, or practiced it sporadically (fig. 5).

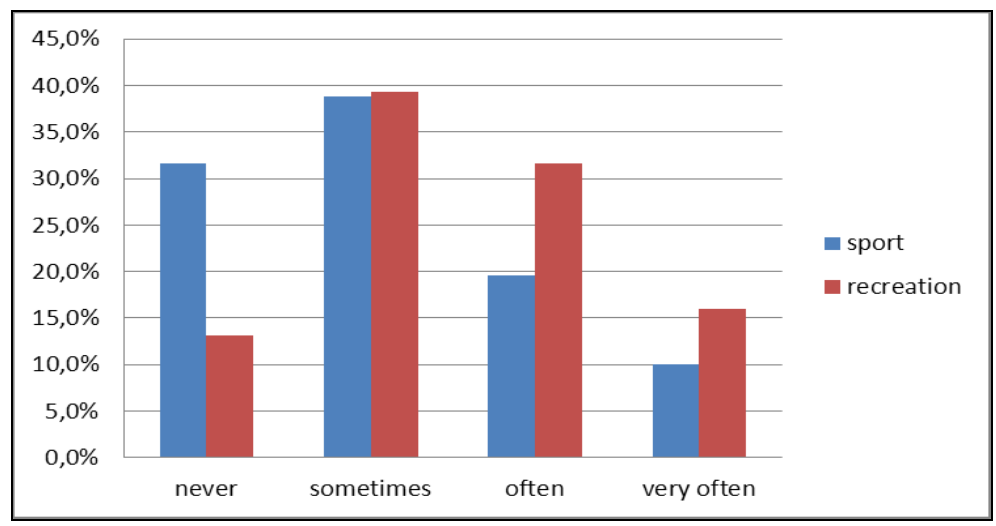

Figure 5. Parents and children's joint psychical activity

The environment in which young people were brought up might have a significant impact on their engagement in physical activities. Subjects revealed that $42.4 \%$ had access to a large number of sport facilities in their neighborhood area, $46.1 \%$ meant there were a few sport facilities around, where as $11.5 \%$ stated there were not enough facilities accessible. Figure 6 presents views on the number of sport facilities indispensable for practicing competitive sports. 


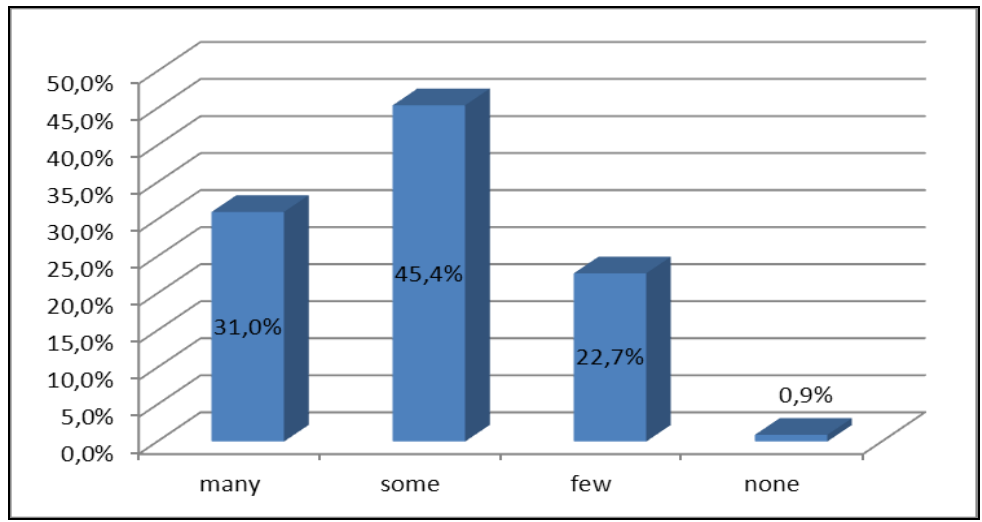

Figure 6. Distribution of local sport facilities indispensable for practicing competitive sports

According to the majority of respondents, the number of local sport clubs was large, as stated by $44.6 \%$ of the subjects. $26.3 \%$ revealed that there were not enough (fig. 7).

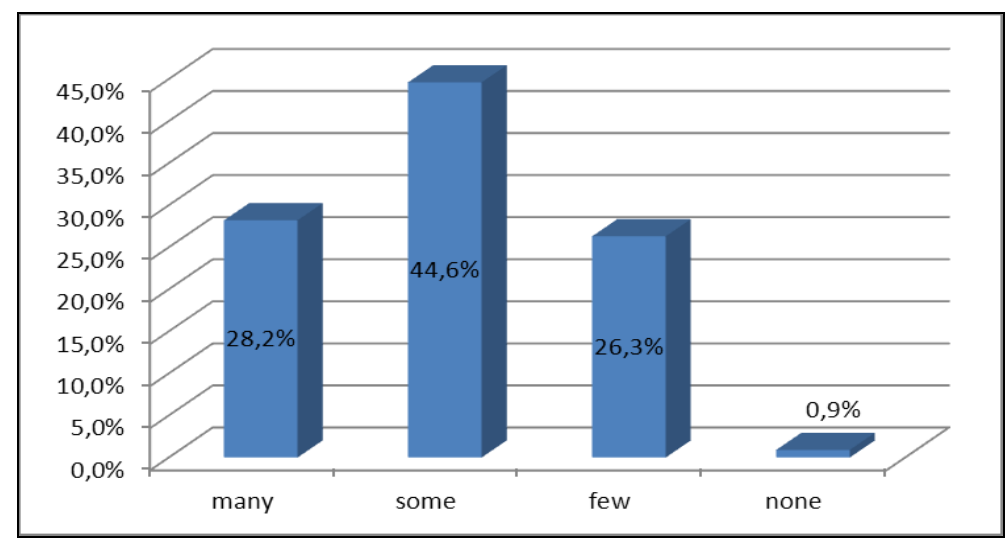

Figure 7. The number of sport clubs and school sport clubs accessible during childhood

According to the subjects, the number of coaches in their school sport clubs was large $(27.3 \%), 50.9 \%$ stated that there were a few, while $21.8 \%$ stated the number of coaches was small.

\section{Discussion}

One of the issues tackled in the research concerns familial determinants of the participation in sport among people included in 
extended sport education programs. We were particularly interested in examining the parents' influence on children's engagement in competitive sport. The research concerning physical activity of the family developed in two main directions. First to a much larger extent discussed in the literature, involves the impact of parents' engagement in physical activities on the psychical activity if their children (Atsalakis \& Sleap 1996; Bauer, et al., 2008; Piech \& Michałowska 2012). Dempsey et al. (1993) highlights the fact that parents' influence is especially important in early childhood. Freedons \& Evenson (1991) prove that active parents are more likely to raise more active children, while inactive parents will have inactive children. Brustad (1993) points out those parents are aware of the significant role they play in the early stage of children's engagement in sport. This is the key area where parents are able to influence a child's activity. Based on that, parents can decide which kind of psychical activity the child will engage in and how they will support his or her participation. Interesting research conducted by Sanchez (2013), where 723 parents and children engaged in sport were included, showed a positive relationship between parents' support of the sport and players' enjoyment and a negative relationship with players' a motivation. Lastly, it was emphasized that appropriate parental participation can promote an increase of players' enjoyment of and motivation for sport. Unfortunately, research conducted by Kaiser (2013), where parents of preschool children were included, showed that most of them were characterised by a declarative attitude towards their children's physical activity. Parents are aware of the need for physical activity of their children but they do not provide it. The author spotlights the cooperation between parents and preschool.

The second direction is more concerned with examining the influence of children's psychical activity on their parents' physical activity (Iannotti, 2005; Piech et al., 2013; Birontiene, 2012). It must be stressed that this phenomenon is not widely depicted in literature and mostly concerns families with younger children.

This follows the typology presented by Mead (1978), in which she identifies post-figurative cultures where children learn mainly from their parents; configurative cultures where both children and adults learn from their peers and finally pre-figurative cultures where adults also learn from their children. As stated by Pawlak (1998), in the field of sport the encouragement to engage in it is intentional and consistent. Taking that into consideration, it is important to discuss the role of family in the introduction to sport and the development of a sport career. The sportive family where one of the parents engages in competitive sport provides an interesting 
issue. It is not to be forgotten that every family, also a non-sportive family, forms the primary environment for a child in his or her engagement in any physical activity. This can be illustrated by the most basic participation of parents and children in leisurely activities and simple sport games. The parents are indeed first psychical educators for their children. They pass on to them the ways of spending leisure time and family sport traditions. As highlighted by Atsalakis and Sleap (1996), it is only logical that including children in various psychical activities is dependent on their parents will and financial support. The results indicate that parents and siblings together with physical education teachers had a smaller impact on the decision to join a sport club than a will to become a professional athlete or sport idol than children's own competitiveness. The main reasons behind staying in a sport club and continuing participation in sport also do not show a significant impact of the family, siblings or physical education teachers. Good coaches, the will to become a professional, friends, as well as early sport achievements and sport idols were more influential factors. These results indicate that young athletes follow the agonistic behaviour pattern. According to Nowak (2013), this model is common among youngsters who engage in sport and it remains a recognizable merit-namely the popularity of sport champions and winners. According to the results most of the parents did not engage in sport (70\% of mothers and over $40 \%$ of fathers). It is, however, crucial to note that Poland falls into the group of countries with a generally low level of adults' engagement in physical activities. The most popular way of spending leisure time in Polish families is watching TV. They also point out the lack of variety of psychical activities that parents and children engage in together. The research conducted by Centre for Public Opinion Research (CBOS 2013) in 2013 is less pessimistic. The results also indicate a positive change. $66 \%$ of adults declare that they exercise, $40 \%$ of them regularly and $26 \%$ sporadically. Psychical activity, however, mostly is a young people's domain. The investigated youngsters regarded sport as the $4^{\text {th }}$ most common way of spending leisure time with their families. Taking into consideration the whole population of Poland, the parents of the studied youngsters exhibited a higher level of involvement in physical activities (Mogit-Lisowska, 2010). A higher percentage engaged in amateur sport compared to competitive sport and fathers appear to be more active than mothers. Engagement of parents and children in physical activities was not systematic. The instances of such behaviour were rare. Literature show that more positive perceptions of social relationships are associated with more positive motivational outcomes, taking into account 
parent-peer group and friendship variables in combination (Ullrich-French $\&$ Smith, 2006).

The research conducted by Domingues and Goncalves (2013) show that the impact of parents is a significant sport mechanism and that it influences young people's participation in sports. This influence has various levels if significance depending on how long an individual has been practicing sport with a high significance during the phase of specialization where attention is directed on dominant competitive and achievementoriented behaviours. Emphasising the supportive role of parents in this professional environment, the research indicate that educational properties of parents were reflected in some of the lifelong social skills found in sport. Another interesting issue is the role the local environment plays in providing conditions that facilitates the practicing of sport. Our subjects highly valued the sport facilities available and the accessibility of sport clubs. This does not, however, mean that there is sufficient access to facilities across the country. On the contrary, the accessibility of such facilities is still unsatisfactory. The investigated youngsters attended schools where these conditions were much better. Only by qualitative actions in organized sports will the youth be able to take full advantage of continuous participation in sport. Parents are important social actors in the talent development programmes due to their strong impact on the attitude and expectations of the young adolescents in a demanding competitive environment. Further research should focus on family microsystems and connections to behaviours displayed by the youth in the process of sport talent development. Brustad (2010) states: "However, we should not lose sight of the fact that the family is the most important form of social influence upon physical activity, and family-based physical activity promotion efforts represent a greatly underutilized and cost-effective resource for the promotion of physical activity. Family-based approaches also have the potential to foster desirable lifestyle habits and enjoyment of physical activity that can facilitate physical activity involvement for a lifetime".

\section{Conclusions}

The results indicate that the influence of parents and physical education teachers on the decision to join a sport club and to continue sport career is rather low.

Main reasons behind joining a sport club are: the desire to become an athlete, sport idols, and the subjects' own will. Staying in a sport club and pursuing a career is also determined by previous achievements in the field and good coaches. 
The parents' past engagement in psychical activities was not systematic. The subjects consider local sport facilities and a number of accessible sport clubs and sports coaches to be of high importance at the early stage of their engagement in sport.

\section{Reference}

1. Atsalakis, M., \& Sleap, M. (1996). Registration of children in a physical activity program: An application of the theory of planned behavior. Pediatric Exercise Science, 8, 166-176.

2. Baker, J., Côté, J. \& Deakin, J. (2005). Expertise in ultra-endurance triathletes: early sport involvement, training structure and the theory of deliberate practice. J. Appl. Sport Psychol, 17, 64-78.

3. Bauer, K. W., Nelson, M. C., Boutelle, K. N., \& Neumark-Setainer, D. (2008). Parental influences on adolescents' physical activity and sedentary behavior. Longitudal findings from Project EAT-II Int. J. Behav. Nutr. Phys. Act., 5(12), 1-7.

4. Birontiene, Z. (2012). A child as a physical activity stimulator in a family. Sporto mokslas, 2(68), 38-44.

5. Brustad, R. J. (1993). Who will go out and play? Parental and psychological influences on children's attraction to physical activity. Pediatric Exercise Science, 5, 210-223.

6. Brustad, R. J. (2010). The role of family in promoting physical activity. President's Council on Physical Fitness and Sports. Research Digest, Series10, No.3.

7. Carlson, R. (2007). From talent to success in competitive sport - example Sweden. Paper presented at the International Conference for Sport Administrator, 16-18 August 2007. Kanyakumari, India.

8. Carlson, R. (2009). Talent development in competitive sport - some theoretical and practical implications. Paper presented at the 3rd International Scientific Symposium in Learning and Teaching Motor Skills. Jyväskylä, Finland.

9. Carlson, R. (2013). Elite training and upper secondary education. Paper presented at the ICCE Global Coach Conference, Sept 11-14, Durban, South Africa.

10. Csikszentmihalyi, M., Rathunde, K. \& Whalen, S. (1993). Talented teenagers - the roots of failure and success. Cambridge: University Press.

11. Centre for Public Opinion Research. (2013). Centrum Badania Opinii Spolecznej (CBOS) - Aktywność Fizyczna Polaków, BS/129/2013, Warszawa.

12. David, P. (2005). Human Rights in Youth Sports. A Critical Review of Children's Rights in Competitive Sports. London: Routledge. 
13. Dempsey, J.M., Kimiecik, J.C., \& Horn, T.S. (1993). Parental influence on children's moderate to vigorous physical activity participation: An expectancy-value approach. Pediatric Exercise Science, 5, 151-167.

14. Domingues, M., \& Goncalves, C.E. (2013). The Role of Parents in Talented Youth Sport. Does Context Matter? Polish Journal of Sport and Tourism, 20(2), 117-122.

15. Freedson, P.S., \& Evenson, S. (1991). Familial aggregation in physical activity. Research Quarterly in Exercise and Sport, 62, 384-389.

16. Iannotti, R. J. (2005). Prospective analyses of relationships between mother and children physical activity. Journal of Physical Activity and Health, 2(1), 1-34.

17. Issurin, V. (2015). Early precursors of athletic talent evidence from a study among Olympic Champions. Journal of Kinesiology and Exercise Science, Vol.25, No. 2(70), 11-16.

18. Kaiser, A. (2013). Socjalizacja do prozdrowotnego wypoczynku w rodzinie i placówkach przedszkolnych. Studia Periegetica, Zeszyty Naukowe WWSTiZ w Poznaniu. 9, 75-88.

19. Kincer, K. (2005). Coach-Athlete relations - connecting with athletes throughout their careers. Champaign, IL: Human Kinetics.

20. Malina, R. (2015). Movement proficiency and talent development in sport. Journal of Kinesiology and Exercise Sciences, Vol.25. No.2 (70), 21.

21. Mead, M. (1978). Kultura $i$ tożsamość. Studium dystansu międzypokoleniowego. MA: PWN Warszawa.

22. Mogit-Lisowska, J. (2010). Rekreacyjna aktywność ruchowa dorostych Polaków-uwarunkowania i styl uczestnictwa. MA: AWF Warszawa.

23. Nowak, M. A. (2013). Physical culture patterns in the life style of the polish society. Polish Journal of Sport and Tourism, 20 (1), 3-12.

24. Pawlak, W. (1998). Sport $w$ rodzinach sportowych. Kobieta kreatorka aktywności sportowej w rodzinie, PSSK Warszawa, MA: Z.Zukowska.

25. Piech, K., Nowak, K., Birontiene, Z., \& Bula-Biteniece, I. (2013). Physical exercises for pre-school children with homework and parents mobilization around these tasks. Polish journal of Sport and Tourism, 20 (3), 217-226.

26. Piech, K. \& Michałowska, A. (2012). Influence of Parents' physical activity on the level of physical activity of family members on example of the Grand Prix Round of South-East Poland Running Competitions. LASE Journal of Sport Science, Vol.3 No. 2, 18-27.

27. Sanchez-Miguel, P. A., Leo, F. M., Sanchez-Oliva, D., Amado D., \& Garcia-Calvo, T. (2013). The importance of Parental Behavior in their Children Enjoyment and Motivation in Sport. Journal of Human Kinetics, 36, 169-177.

28. Soberlak, P. \& Cotè, J. (2003). The development activities of elite icehockey players. J. Appl. Sport Psychol., 15, 41-49. 
29. Wolfenden, L. \& Holt, N. L. (2005). Talent development in elite junior tennis: perceptions of players, parents and coaches. J. Appl. Sport Psychol., 17, 108-126.

30. Ullrich-French, S., \& Smith, A. L. (2006). Perceptions of relationships with parents and peers in youth sport: Independent and combined prediction of motivational outcomes. Psychology of Sport and Exercise, 7, 193-214.

Submitted: November 14, 2016

Accepted: December 27, 2016 